\title{
O ABORTO COMO ACONTECIMENTO NA OBRA DE ANNIE ERNAUX
}

\section{ABORTION AS A HAPPENING IN ANNIE ERNAUX'S WORK}

\author{
Elisa Fernandes Rodrigues ${ }^{1}$ e Sandra Dias Loguercio ${ }^{2}$
}

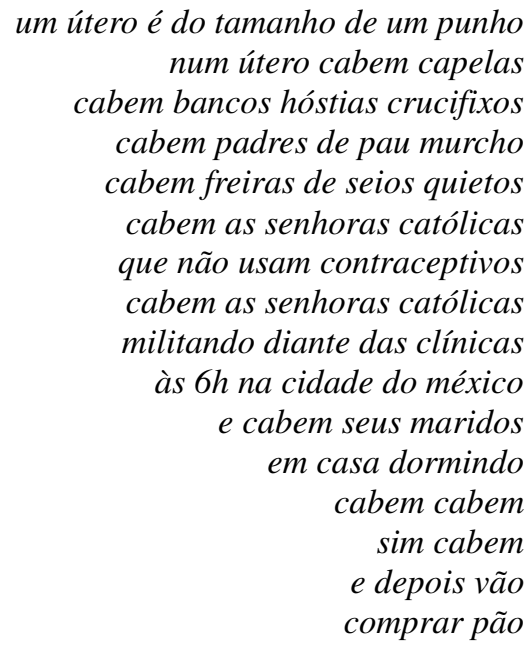

Angélica Freitas, Um útero é do tamanho de um punho.

RESUMO: O presente artigo parte de um trabalho de tradução do francês para o português do romance autobiográfico L'événement (2000), em que a escritora Annie Ernaux relata e repensa o aborto clandestino que viveu em 1964, na França, a fim de elaborar esse acontecimento traumático. Temos por objetivo apresentar a autora do romance e as características de sua obra, além de refletir acerca da narrativa autobiográfica e da escrita feminina. Como o papel político da escrita é central para a autora, discute-se também a realidade do aborto na França, país onde a prática é legal desde 1975, o que consistiu em uma das principais motivações para a tradução do livro para o Brasil.

PALAVRAS-CHAVE: Tradução literária; Gênero autobiográfico; Annie Ernaux.

ABSTRACT: This article is based on a paper about the Brazilian Portuguese translation of the French autobiographical novel L'événement (2000), in which author Annie Ernaux describes and reconsiders an illegal abortion she had in France, 1964. Further discussing this traumatic experience she underwent, the study aims to introduce the writer of the novel and the aspects of her work, as well as to reflect on the autobiographical narrative and women's writing. Since the political role of writing is central to the author, this paper also examines the history of abortion in France, where it has been legal since 1975, one of the main motives for translating the book into Brazilian Portuguese. 
KEYWORDS: Literary translation; Autobiographical genre; Annie Ernaux.

\section{Sobre a proposta de tradução}

Em seu romance autobiográfico L'événement (2000), traduzido por $O$ acontecimento ${ }^{3}$, a escritora francesa Annie Ernaux fala sobre sua vivência de um aborto realizado em 1964, aos 23 anos de idade, quando essa ainda era uma prática ilegal na França. Além da possibilidade de refletir sobre as particularidades da tradução de textos literários autobiográficos, a discussão sobre o aborto e suas realidades na França e no Brasil foram uma das principais motivações para o projeto de tradução dessa obra, ilustrada aqui pelo trecho que segue:

Senti uma vontade incontrolável de cagar. Corri para o banheiro, do outro lado do corredor, e fiquei de cócoras na frente da privada, encarando a porta. Eu enxergava o azulejo entre minhas coxas. Fazia o máximo de força que podia. Aquilo estourou como uma granada, em um esguicho de água que respingou até a porta. Enxerguei um bonequinho pendurado ao meu sexo por um cordão avermelhado. Não tinha me passado pela cabeça ter aquilo dentro de mim. Eu tinha que voltar caminhando com aquilo até o quarto. Peguei-o com uma mão - ele era estranhamente pesado - e me lancei no corredor segurando-o com firmeza entre as coxas. Eu era um bicho.

A porta de O. estava entreaberta, a luz acesa, eu a chamei suavemente, "pronto".

Estamos as duas em meu quarto. Estou sentada na cama com o feto entre as pernas. Não sabemos o que fazer. Digo a O. que é necessário cortar o cordão. Ela pega uma tesoura, não sabemos em que ponto se deve cortar, mas ela corta mesmo assim. Ficamos olhando aquele corpo minúsculo, de cabeça grande, sob as pálpebras transparentes os olhos são duas manchas azuis. Praticamente uma boneca indígena. Olhamos a genitália. Parece o começo de um pênis. Então, eu consegui gerar aquilo. O. se senta no banquinho, ela chora. Nós choramos silenciosamente. É uma cena sem nome, a vida e a morte ao mesmo tempo. Uma cena de sacrifício.

Não sabemos o que fazer com o feto. O. vai buscar no quarto um pacote vazio de torradinhas e eu o despejo ali dentro. Vou até o banheiro com o pacote. É como se carregasse uma pedra. Viro o pacote na privada. Puxo a descarga.

No Japão, chamam os embriões abortados de "mizuko", os filhos da água. momento.

Os gestos da noite se fizeram sozinhos. Não havia mais nada a fazer naquele

Com suas crenças e seu ideal burguês, $\mathrm{O}$. não estava preparada para cortar o cordão de um feto de três meses. Neste momento, talvez ela esteja se lembrando desse episódio como uma desordem inexplicável, uma anomalia em sua vida. Talvez ela condene os abortos provocados. Mas é ela, cujo rosto delicado revejo contrariado e aos prantos, apenas ela que estava ao meu lado, naquela noite, no papel improvisado de parteira, no quarto 17 da cité universitaire des filles ${ }^{4}$. (ERNAUX, 2000, p. 90-2)

3 Tradução de autoria de Elisa Fernandes Rodrigues, realizada como parte do Trabalho de Conclusão de Curso em Bacharelado em Letras intitulado $O$ acontecimento em tradução: sobre a reescrita autobiográfica em Annie Ernaux (RODRIGUES, 2016), que teve por objetivo apresentar uma tradução comentada.

4 A escolha pela tradução de "cité des filles" por "cité universitaire des filles", que de início pode causar certo estranhamento, justifica-se pelo projeto de tradução adotado para a obra, em que se busca realizar uma tradução permeável, mantendo ou 
O projeto de tradução do livro foi delimitado levando-se em conta as particularidades do gênero autobiográfico, em especial o papel central das referências culturais — relativas a lugares, fatos históricos, músicas, livros, entre outras - na narrativa. A importância dessas referências na obra está no fato de demarcarem um acontecimento único — vivido e transmitido como tal —, o que motivou a escolha por uma tradução permeável, segundo definição de Benedetti (2003, p. 28), diretriz que permite enfatizar a subjetividade característica do texto autobiográfico. Além disso, deu-se atenção igualmente ao ritmo da prosa, visto sobretudo na sintaxe do texto, e à relação entre língua e cultura. Não comentaremos aqui, porém, a tradução proposta; falaremos, antes, do que a motivou: a autora, sua obra, a narrativa autobiográfica e a mulher que se autobiografa, bem como sobre o aborto, situando historicamente as políticas públicas na França relativas ao tema, e o papel político da obra e de sua tradução.

\section{A autora}

Ernaux nasceu em 1940 na cidade de Lillebonne, região da Normandia, na França. Como raras meninas na época, foi incentivada aos estudos, cursou Letras e tornou-se escritora e professora

forjando elementos e marcas culturais do francês, a fim de reforçar o caráter autobiográfico da obra e, de certa forma, trazer o leitor para o universo do relato. Para mais informações sobre o projeto de tradução, ver RODRIGUES, 2016.

5

No texto de partida:

"J'ai ressenti une violente envie de chier. J'ai couru aux toilettes, de l'autre côté du couloir, et je me suis accroupie devant la cuvette, face à la porte. Je voyais le carrelage entre mes cuisses. Je poussais de toutes mes forces. Cela a jailli comme une grenade, dans un éclaboussement d'eau qui s'est répandue jusqu'à la porte. J'ai vu un petit baigneur pendre de mon sexe au bout d'un cordon rougeâtre. Je n'avais pas imaginé avoir cela en moi. Il fallait que je marche avec jusqu'à ma chambre. Je l'ai pris dans une main — c'était d'une étrange lourdeur — et je me suis avancée dans le couloir en le serrant entre mes cuisses. J'étais une bête.

La porte de O. était entrebâillée, avec de la lumière, je l'ai appelée doucement, «ça y est ».

Nous sommes toutes les deux dans ma chambre. Je suis assise sur le lit avec le foetus entre les jambes. Nous ne savons pas quoi faire. Je dis à $\mathrm{O}$. qu'il faut couper le cordon. Elle prend des ciseaux, nous ne savons pas à quel endroit il faut couper, mais elle le fait. Nous regardons le corps minuscule, avec une grosse tête, sous les paupières transparentes les yeux font deux taches bleues. On dirait une poupée indienne. Nous regardons le sexe. Il nous semble voir un début de pénis. Ainsi j'ai été capable de fabriquer cela. O. s'assoit sur le tabouret, elle pleure. Nous pleurons silencieusement. C'est une scène sans nom, la vie et la mort en même temps. Une scène de sacrifice.

Nous ne savons pas quoi faire du foetus. O. va chercher dans sa chambre un sac de biscottes vide et je le glisse dedans. Je vais jusqu'aux toilettes avec le sac. C'est comme une pierre à l'intérieur. Je retourne le sac au-dessus de la cuvette. Je tire la chasse.

Au Japon, on appelle les embryons avortés « mizuko », les enfants de l’eau.

Les gestes de la nuit se sont faits tout seuls. Il n'y en avait pas d'autres à faire à ce moment-là.

Par ses croyances et son idéal bourgeois O. n'était pas préparée à couper le cordon d'un foetus de trois mois. À l'heure qu'il est, peut-être se rappelle-t-elle cet épisode comme un désordre inexplicable, une anomalie dans sa vie. Peut-être condamnet-elle les IVG. Mais c'est elle, dont je revois la petite figure rechignée en pleurs, elle seule qui était à côté de moi, cette nuit-là, dans le rôle improvisé d'une sage-femme, chambre 17, de la cité des filles." 
universitária. Annie Ernaux já publicou mais de vinte livros, escritos sobretudo em prosa autobiográfica, e já foi agraciada com mais de cinco prêmios literários, como o Prix Renaudot, em 1984, pela obra La Place (Gallimard), o Prix de la langue française, em 2008, e, recentemente, o Prix Marguerite Yourcenar, em 2017, ambos pelo conjunto da obra. Seu último romance, Mémoire de fille, foi lançado em 2016. Apesar de bastante conhecida na França - encontramos mais de 15 teses já defendidas ou em preparação sobre a obra da autora em universidades francesas ${ }^{6}$ —, há poucos estudos no Brasil sobre sua obra ${ }^{7}$ e apenas duas traduções de seus livros para o português brasileiro, indisponíveis atualmente no mercado.

\section{A obra e o gênero autobiográfico}

A escrita de Ernaux é atravessada pela sociologia, pela reflexão acerca das relações pessoais e pelo feminismo. A respeito desse último, El Sakezli (2013) chama a atenção para o fato de que Ernaux é influenciada pelas leituras de George Sand e Simone de Beauvoir, duas escritoras que se inscrevem no universo, majoritariamente masculino, da "literatura pessoal" (EL SAKEZLI, 2013, p. 11), autobiográfica, fazendo de suas obras literárias um lugar de luta contra uma cultura moldada segundo a visão masculina da história e da sociedade. Como elas, a autora da qual tratamos não esconde seu engajamento à causa das mulheres, manifesta em sua trajetória literária e em suas entrevistas.

Annie Ernaux entende o aborto que realizou como um acontecimento, isto é, como aquilo que acontece conosco e que nos transforma (ERNAUX, 2017). Contudo, é apenas trinta e cinco anos após a vivência do aborto provocado que a escritora francesa conseguirá falar sobre o assunto no romance L'événement. A escrita do livro - não apenas deste, como também de grande parte de sua obra, majoritariamente autobiográfica — é realizada como tentativa de elaboração de um acontecimento traumático. Ernaux busca reviver essa história, reconciliar-se com seu passado e ressignificar uma vivência dolorosa, transformando-a em algo criativo.

O romance insere-se, assim, na literatura dita íntima, da qual fazem parte gêneros como o ensaio, as memórias, as confissões, o diário, o autorretrato, a biografia, a autobiografia, entre outras formas possíveis. No caso da autobiografia, Lejeune a define como "narrativa retrospectiva em prosa que uma pessoa real faz de sua própria existência, quando focaliza sua história individual, em particular a história de sua personalidade" (LEJEUNE, 2008, apud BRANCO; BUNGART NETO, 2017, p. 160). Mesmo que as fronteiras entre gêneros literários sejam muitas vezes tênues, em razão da sobreposição de características ou da ausência de algumas delas, o gênero autobiográfico se

Conforme consulta realizada à plataforma online www.theses.fr em agosto de 2017.

Apenas duas dissertações de Mestrado, conforme consulta realizada à plataforma Sucupira em www.sucupira.capes.gov.br em agosto de 2017. 
distinguiria dos demais pela identidade entre autor (pessoa real), narrador e personagem principal (os sujeitos da narrativa).

Bakthin complexifica essa relação ao escrever:

Entendo por biografia ou autobiografia (descrição de uma vida) a forma transgrediente imediata em que posso objetivar artisticamente a mim mesmo e minha vida. Vamos examinar a forma da biografia apenas naqueles sentidos em que ela pode servir para a autoobjetivação, isto é, ser autobiografia, ou seja, do ponto de vista de uma eventual coincidência entre a personagem e o autor nela, ou melhor (porque coincidência entre personagem e autor é contradictio in adjecto, o autor é elemento do todo artístico e como tal não pode coincidir dentro desse todo com a personagem, outro elemento seu. A coincidência pessoal "na vida" da pessoa de quem se fala com a pessoa que fala não elimina a diferença entre esses elementos no interior do todo artístico. Pode-se perguntar como eu represento a mim mesmo diferentemente da pergunta: quem sou?), do ponto de vista do caráter particular do autor em sua relação com a personagem. (BAKHTIN, 2011, p. 139, grifo do autor)

Embora a sobreposição autor-personagem (e neste caso também narrador) se dê segundo determinado ponto de vista, como expõe Bakhtin, certamente existe entre eles um ponto de convergência, isto é, personagem-narrador remetem ao autor e este, por sua vez, apresenta-se, através de uma construção artística, através dessas vozes e da relação particular que estabelece com elas ao se auto-objetivar.

Essa forma de narrativa eleita pela autora coloca em cena, de todo modo, três elementos inextricáveis em sua obra: a quête de soi (busca de si mesma), a escrita e a memória - estando os dois últimos provavelmente a serviço do primeiro. Por meio da memória, Ernaux revisita sua história tentando entender quem é e em que sentido seu eu-passado é ou deixa de ser seu eupresente. Trata-se de uma busca pelo autoconhecimento que se dá através da escrita e que parece ser própria a toda narrativa autobiográfica na medida em que:

[...] a escrita autobiográfica expõe o "eu" como objeto de pesquisa e de questões. A identidade que parece ter se dispersado entre as fases da vida do autor se torna o próprio tema de suas preocupações. O objetivo, nesse caso, passa a ser o de reencontrar uma certa unidade na desordem inspirada por esse "eu". ${ }^{\text {(EL SAKEZLI, 2013, p. 10) }}$

\section{A autobiografia de mulher}

Além disso, o projeto de escrever a vida — não a própria vida, não uma vida, mas a vida — guia a escrita da autora. Ernaux trabalha incessantemente com o contraponto entre o interno e o externo, entre o particular e o universal. A autora parte do princípio de que todos lidam com as

8 Todas as traduções de citações escritas originalmente em francês são de nossa responsabilidade. No texto de partida: “Traditionnellement, l'écriture autobiographique expose le «moi » comme sujet de recherche et objet d'interrogations. L'identité qui semble éparpillée à travers les âges de l'auteur devient le domaine même de ses préoccupations. L'objectif étant de retrouver une certaine unité dans le désordre qu'inspire ce « moi »." 
mesmas questões - o corpo, a sexualidade, a educação, a doença, a trajetória social, a relação com os outros, o luto - , mas as experienciam de forma individual. Desse modo, ela se serve de sua vida como matéria, mergulhando e explorando experiências pessoais, para buscar alcançar uma verdade própria da sensibilidade humana. Nesse sentido, uma das proezas de seus livros é permitir que o leitor pense sobre si mesmo e sinta através do Outro.

O leitor a que nos referimos aqui, que mais provavelmente se identificará com a obra de Annie Ernaux, é sobretudo a leitora: é a mulher ocidental que viveu durante ou após a revolução sexual dos anos 1960 e 1970, após a criação do anticoncepcional, que permitiu que a mulher tivesse mais controle sobre a gravidez e liberdade em suas relações sexuais, podendo escolher quando e até mesmo se deseja ter filhos. É a mulher sensível à luta por condições mais igualitárias de participação e representação social no tocante ao gênero, que já pode ocupar outros espaços sociais que não apenas o de mãe e dona de casa.

Ernaux parece lidar permanentemente com a questão do feminino, assim como do feminismo. Desse modo, cabe neste contexto refletir sobre as questões levantadas por Ana Cristina Cesar nos ensaios "Rio corrente, depois de Eva e Adão..." e "Excesso inquietante" (CESAR, 1999): existiria uma "literatura de mulher"? Se sim, em que sentido uma literatura feminina seria distinta de uma literatura masculina - pela temática, pela forma? É fácil constatar que Ernaux trata de temáticas inerentes ao feminino, como o aborto, em L'événement; mas também "femininamente", como chamaria Ana C., isto é, “de forma errante, descontínua, desnivelada, expondo com intensidade muito sentimento em estado bruto" (Ibid., p. 249). Isso pode estar relacionado à maneira como a mulher ${ }^{9}$ vive, desde cedo, as mudanças constantes de seu corpo - através da menstruação, contracepção, aborto, gravidez, amamentação, menopausa —, mas também a aspectos culturais, se entendermos o gênero e a feminilidade, à qual também está associada a noção de maternidade, como construções sociais.

Cabe ressaltar que Ana Cristina Cesar não se faz essas perguntas ingenuamente, sem levar em conta a carga pejorativa presente em tudo aquilo que é dito "de mulher". Costuma-se falar, por exemplo, em "literatura de mulher" para se referir a uma literatura menos valorizada, mais comercial, dita "barata" e "fútill", que trata principalmente de romances de forma rasa, idealizada, sem suscitar grandes reflexões ou questionamentos. Ana C. levanta essas questões pensando menos no público-leitor e mais no processo de escrita: o fato de o texto ser escrito por uma mulher influencia e deixa marcas em sua produção, em sua forma de se expressar e interagir com o mundo? $\mathrm{E}$, se parece que sim, de que forma? Talvez não haja resposta ou uma só resposta para os questionamentos da poeta. Cremos, porém, que eles estejam em jogo quando se lê e traduz Ernaux.

9 Refere-se aqui essencialmente às mulheres cisgêneras, cuja identidade de gênero corresponde ao gênero designado no nascimento, com base no sexo biológico. 


\section{O aborto, tema da narrativa, e o debate na França a partir dos anos 60}

Quanto à narrativa de L'événement, o romance começa pelo dia em que Annie, personagem principal e narradora do livro, está esperando o resultado de um teste para HIV — não sabemos exatamente quando, mas com certeza a partir dos anos oitenta, uma vez que a AIDS foi identificada em 1981 —, situação que a remete para o momento em que, em 1963, aos 23 anos, esperava o médico confirmar se estava grávida ou não. É essa associação que introduz o relato sobre o aborto vivenciado pela escritora em 1964, após a confirmação da gravidez.

Cabe lembrar que em 1964 o aborto ainda era uma prática ilegal na França. Até a implementação da lei Neuwirth, em 1967, era inclusive proibido o uso de todo e qualquer método contraceptivo no país. Atualmente, a IVG, interrupção voluntária da gravidez — como é chamado na França o aborto provocado realizado por motivos não médicos — é legal e entendida como um direito de escolha da mulher (conforme artigo L.2212-1 do Código da Saúde Pública da legislação francesa).

Esse direito foi conquistado em 17 de janeiro de 1975 com a lei Veil, depois de um período de duras repressões àquelas — normalmente as faiseuses d'anges, nome dado às aborteiras — que praticassem o aborto, culminando até em pena de morte, principalmente na França de Vichy, como o famoso caso de Marie-Louise Giraud. A aprovação dessa lei foi consequência do engajamento do movimento feminista do começo dos anos 1970, especialmente do Movimento das 343 (1971) petição publicada pela revista Le Nouvel Observateur assinada por 343 mulheres, dentre elas diversas celebridades como Simone de Beauvoir e Catherine Deneuve, que declararam já terem feito um aborto - , e do processo de Bobigny, de 1972, em que quatro mulheres além da vítima foram julgadas por terem auxiliado uma menina de 17 anos, grávida em consequência de um estupro, a abortar.

A lei Veil apresentava, no entanto, limitações, pois previa a possibilidade de aborto apenas para quando a mulher estivesse em situação de détresse, isto é, de desespero, desamparo, angústia. Somente em 2014, com a lei Vallaud-Belkacem, há uma atualização do texto legal, eliminando-se a noção, bastante subjetiva, de détresse, e prevendo multa para o impedimento de acesso ou distorção de informações relacionadas à IVG.

Atualmente uma IVG pode ser praticada na França até o fim da $12^{\mathrm{a}}$ semana de gravidez ou até a $14^{\mathrm{a}}$ semana de amenorreia ${ }^{10}$. Todas as mulheres grávidas podem decidir por uma IVG, sejam elas maiores ou menores de idade, e mesmo estrangeiras, podendo o pedido do aborto ser feito

10 Já o aborto por razão médica é realizado quando a gravidez coloca a vida da mulher em risco ou quando o feto tem alguma doença grave e incurável; nesse caso, o aborto pode ser realizado até o último momento da gravidez. 
apenas por elas. Esse direito passou a ser garantido pelo reembolso de 100\%, a partir de 2016, da seguridade social francesa. Em suma, entende-se que o aborto é um fato social, uma escolha afetada por aspectos econômicos, legais, políticos, ambientais, emocionais, éticos, entre outros que as mulheres fazem desde sempre, e por isso é tratado como uma questão de política de saúde pública.

\title{
O papel político da obra
}

Também está em questão no livro L'événement o posicionamento feminista da autora. Além de o livro abordar uma experiência eminentemente feminina, a autora discute a condição da mulher nos anos 1960 na França, relatando e contestando, embora não explicitamente, a violência com que foi tratada pelos amigos, médicos e funcionários do hospital por ser uma mulher solteira, não virgem e por ter decidido recorrer ao aborto. Ernaux trata desse tema e das questões que dizem respeito ao corpo e à sexualidade da mulher sem tabu ou culpabilidade, transgredindo o silêncio imposto pela sociedade. Sobre esse acontecimento em sua vida, a autora diz em uma entrevista à editora Gallimard ${ }^{11}$ :

\begin{abstract}
Essa lembrança nunca me abandonou. Ela representa em minha vida, como, acredito, na de muitas mulheres, seja antes ou depois da lei Veil de 1975, um acontecimento no verdadeiro sentido da palavra, isto é, algo que acontece conosco e que nos transforma. O que não quer dizer que não se possa abafálo em seguida, o que foi o meu caso. Esse tipo de acontecimento feminino por excelência, que diz respeito à vida, como o parto, é, aliás, abafado mais uma vez, como se o discurso médico impedisse as mulheres de se pensar e se dizer. [...] Essa foi uma experiência da vida e da morte que me estruturou fortemente, que me deu uma outra visão de mundo. Tudo isso veio vindo progressivamente. Mas eu não ousava falar no assunto, uma espécie de silêncio interior tinha se instalado. Há algo que pesa sobre tudo o que diz respeito à experiência propriamente feminina e que faz com que seja muito difícil falar sobre ela, a despeito do que se diz sobre a libertação das mulheres. [...] Primeiramente, havia o silêncio dos anos 60, porque toda mulher que tinha "passado por aquilo", como se costumava dizer, sentia-se culpada. Depois, as mulheres falaram sobre o que aconteceu com elas, mas no contexto da luta pela legalização do aborto. Eu mesma fiz parte de um
\end{abstract}

11 No texto de partida: “Ce souvenir-là ne m'a jamais quitté. Il représente dans ma vie, comme, je crois, dans celle de nombreuses femmes, que ce soit avant ou après la loi Veil de 1975, un événement au vrai sens du terme, c'est-à-dire quelque chose qui arrive et vous transforme. Cela dit, on peut très bien l'occulter par la suite, ce qui a été mon cas. Ce type d'événement féminin par excellence, qui concerne la vie, comme l'accouchement, est d'ailleurs de nouveau occulté, comme si le discours médical empêchait les femmes de se penser et de se dire. [...] C'était une expérience de la vie et de la mort qui m'avait fortement structurée, qui m'avait donnée une autre vision sur le monde. Tout cela est venu progressivement. Mais je n'osais pas le dire, une sorte de silence intérieur s'était installée. Il y a quelque chose qui pèse sur tout ce qui relève de l'expérience proprement féminine et qui fait qu'elle a beaucoup de mal à se dire, en dépit de ce que l'on raconte sur la libération des femmes. [...] D'abord, il y avait le silence des années soixante, parce que toute femme qui en était " passée par là », comme on disait, se sentait coupable. Ensuite, les femmes ont dit ce qui leur était arrivé, mais dans le contexte de la lutte pour la libéralisation de l'avortement. J'ai moi-même fait partie de ces groupes et j'ai raconté, pour un « livre noir » de l'avortement, ma propre expérience, mais sous un tout autre aspect. J'ai toujours du mal à expliquer pourquoi il est si difficile d'en parler. Peut-être parce que si l'on en parle autrement qu'en termes de « choix de la femme », etc., on est tout de suite vaguement suspecté d'être « contre ». On se tait sur l'expérience réelle de l'avortement. Il y a, par exemple, une chose que je n'ai jamais dite avant de l'avoir écrite : c'était que j'étais fière d'avoir subi cette épreuve-là. Comment expliquer cette fierté ? C'était pour moi comme une expérience initiatique, l'épreuve du réel absolu." 
grupo desses e contei, para um "livro negro" do aborto, minha própria experiência, mas por um viés completamente diferente.

Sempre tive dificuldade de explicar por que é tão complicado falar sobre isso. Talvez porque, se falarmos de outra forma que não em termos de "escolha da mulher", etc., surja de imediato uma vaga suspeita de que somos "contra". O fato é que acabamos nos calando sobre a real experiência do aborto. Há, por exemplo, uma coisa que nunca tinha dito antes de tê-la escrito: que eu tinha orgulho de ter passado por aquela provação. Como explicar esse orgulho? Foi para mim como uma experiência iniciática, a provação do real absoluto. (ERNAUX, 2017)

Como se não fosse o bastante, o livro de Ernaux vai além dessa experiência. Ele também trata, com a mesma importância, do significado da escrita para a autora. Pode-se pensar que esse tema é levantado porque a escrita tem um lugar fundamental em sua vida, em seu processo de autoconhecimento, de elaboração e de compreensão da sua história.

A parteira e antropóloga mexicana Naolí Vinaver atribui outros significados à maternidade quando diz que

As mulheres têm uma consciência corporal nata e todas temos uma sabedoria ancestral de grande honra: o dom da vida. Algumas dão à luz crianças, com braços e pernas. Outras dedicam sua criatividade, concentração, foco, amorosidade, a gerar vida em forma de projetos, ideias, arte. (SANTANA, 2016, p. 32)

É verdade que o acontecimento de Annie Ernaux não deu à luz uma criança, mas gerou, sim, frutos, como a obra literária de que falamos, além de uma intensa e íntima experiência de autoconhecimento. Ernaux (2000) também comenta que essa foi uma provação e um sacrifício necessários para que, depois, ela aceitasse a "violência da reprodução", em suas palavras (p. 111), e deixasse nascer dentro de si o desejo de ter filhos.

Fica claro que a escrita de L'Événement também acaba cumprindo um papel político. Sobre a escrita, a autora diz: "Escrever é, para mim, uma atividade política, que pode contribuir para a revelação e mudança do mundo ou, ao contrário, reforçar a ordem social, moral existente" (ERNAUX, 2003, p. 74) $)^{12}$.

Desse modo, a leitura deste livro em um contexto social como o Brasil, onde o aborto provocado é ilegal e onde há uma onda crescente de conservadorismo, ajuda a alimentar o debate das questões trazidas principalmente pelos movimentos feministas, mas de modo algum limita-se às mulheres ou a qualquer segmento da sociedade. Embora possa haver uma identificação mais fácil por parte de leitoras, já que a obra é escrita da perspectiva da personagem-narradora, em primeira pessoa, quase nos moldes de um diário, talvez seja ao leitor que o texto mais evidentemente se revele ao tratar com objetividade, vigor e crueza de uma experiência exclusivamente feminina. Nesse sentido, arte e vida, que não são a mesma coisa, interligam-se: "Pelo que vivenciei e

12 No texto de partida: “Écrire est, selon moi, une activité politique, c'est-à-dire qui peut contribuer au dévoilement et au changement du monde ou au contraire conforter l'ordre social, moral existant." 
compreendi na arte, devo responder com a minha vida para que todo o vivenciado e compreendido nela não permaneçam inativos" (BAKTHIN, 2011, p. XXXIII) ${ }^{13}$.

\section{REFERÊNCIAS}

BAKHTIN, Mikhail. Estética da criação verbal. Tradução de Paulo Bezerra. 6.ed. São Paulo: Editora WMF Martins Fontes, 2011.

BENEDETTI, Ivone Castilho. Prefácio. In: BENEDETTI, Ivone; SOBRAL, Adail (Org.). Conversas com tradutores: balanços e perspectivas da tradução. São Paulo: Parábola, 2003. p. 1731.

BRANCO, Marta Roque; BUNGART NETO, Paulo. Literatura íntima: que mistérios tem o diário de Alice?. Revista Entrelaces, v. 2, n. 9, p. 157-172, 2017.

CESAR, Ana Cristina. Crítica e tradução. São Paulo: Editora Ática, 1999.

EL SAKEZLI, Oreida. Recherche identitaire et mémoire collective dans l'œuvre d'Annie Ernaux. Thèse de Doctorat, Université François Rabelais de Tours, 2013, 188 p.

ERNAUX, Annie. Entretien: L'événement d'Annie Ernaux. Paris: Gallimard, 2017. Disponível em: $<$ http://www.gallimard.fr/Media/Gallimard/Entretien-ecrit/Entretien-Annie-Ernaux-L-

Evenement/(source)/143868>. Acesso em 03 de set. 2017.

ERNAUX, Annie. L'écriture comme un couteau. Paris: Stock, 2003.

ERNAUX, Annie. L'événement. Paris: Éditions Gallimard, 2000.

FREITAS, Angélica. Um útero é do tamanho de um punho. São Paulo: Cosac Naify, 2012.

RODRIGUES, Elisa Fernandes. O acontecimento em tradução: sobre a reescrita autobiográfica em Annie Ernaux. Trabalho de Conclusão de Curso. Universidade Federal do Rio Grande do Sul, Instituto de Letras, 2016, $80 \mathrm{p}$.

SANTANA, Bianca. No útero, no imaginário, no cotidiano. Revista CULT, São Paulo, n. 216, ano 19, p. 32-35, set. 2016.

13 Agradecemos ao tradutor Luiz Victor Lendengues de Oliveira pela excelência na versão do resumo, à Professora Patrícia Chittoni Ramos Reuillard pela leitura e discussão da tradução do trecho inicial do livro, no contexto da disciplina de Tradução do Francês IV (2016), que motivaram o interesse pela continuidade deste projeto de tradução e, finalmente, ao Professor Robert Ponge e à Professora Beatriz Cerisara Gil pela releitura e pelas inúmeras contribuições dadas à redação final deste texto. 